\title{
Becquerel per Milliliter
}

National Cancer Institute

\section{Source}

National Cancer Institute. Becquerel per Milliliter. NCI Thesaurus. Code C71167.

A metric unit of volumetric radioactivity concentration defined as a concentration of a radionuclide with an activity equal to one becquerel per unit volume equal to one milliliter or one kilobecquerel per liter. 